\title{
Fraud dalam Perspektif Islam
}

\author{
Safuan $^{1 *}$, Ismartaya ${ }^{2}$, Budiandru $^{3}$ \\ Universitas Jayabaya, Universitas Djuanda, Universitas Muhammadiyah Prof. Dr. Hamka. \\ safuan@jayabaya.ac.id, ismartaya@unida.ac.id, budiandru@uhamka.ac.id.
}

*Corresponding Author

Submitted: October 26, 2020

Accepted: January 18, 2021

Published: February 8, 2021

\begin{abstract}
Islam regulates all the problems of its people, one of which is regulated by Islam, namely the relationship between humans. This study aims to try to reveal how cheating or cheating behavior is in an Islamic perspective. The investigation technique used in this study is a qualitative method with a literature review approach where the researcher collects some literature from both international and national journals. The data taken from these journals are then used as study material in writing this research. The results of the study illustrate that Islam has provided clues or signs of cheating or fraudulent behavior through the Koran and Hadith. From the results of the study, it is known that Islam has regulated all the problems of its people, especially the problem of fraud, Islam forbids its followers to do this. In addition, this research reveals that the practice of deception or what is known as cheating has existed for centuries, and Islam has clearly and emphatically provided a picture of how fraud occurs and how the impact of punishment on its followers. This research is also expected to contribute to knowledge related to fraud or fraudulent practices as well as a contribution to enlightenment for society.
\end{abstract}

Keywords: fraud; hadis; Islam; Qur'an.

\section{PENDAHULUAN}

Berbicara terkait permasalahan fraud atau kecurangan tidak lepas dari perilaku masyarakat suatu negara yang diukur dalam indeks korupsi global. Tercatat dalam indeks tersebut, Negaranegara yang berpenduduk mayoritas beragama Islam masuk di dalam negara yang masuk dalam peringkat yang tertinggi dari daftar 180 negara. Menurut tranparency.org tercatat Somalia, Sudan Selatan, Suriah, Yaman, Sudan dan Libia masuk dalam kisaran peringkat 170 - 180 dari 180 negara dengan skor terendah yang berarti tingkat korupsi di negara tersebut cukup tinggi. Lalu bagaimana dengan Indonesia yang merupakan jumlah penduduknya mayoritas Islam?, masih menurut tranparency.org Indonesia berada di peringkat 102 dari 180 negara sehingga dapat disimpulkan bahwa tingkat korupsi di Indonesia masih cukup tinggi dibandingkan dengan Malaysia yang berada di peringkat 57 dan Brunei Darussalam yang berada di peringkat 35. Bagi Indonesia peringkat tersebut menjadi indikasi perlunya upaya yang sangat kuat baik dari pemerintah maupun masyarakat untuk bahu membahu memberantas budaya korupsi ini secara bersama.

Fraud/korupsi merupakan bentuk tindakan curang yang bertujuan untuk memperoleh sesuatu yang bukan menjadi haknya untuk kepentingan baik individu maupun kelompok. Fraud ini bukan merupakan respresentasi dari agama tertentu yang dianut oleh pelakunya, semua agama tidak pernah mengajarkan perbuatan nista seperti itu. Namun, penggambaran media massa baik cetak, elektronik maupun digital terhadap pelaku fraud/korupsi yang selalu dikaitkan dengan agama tertentu khususnya Islam. Hal ini perlu mendapatkan pencerahan khususnya untuk masyarakat yang sudah terlanjur kurang mendapatkan informasi yang objektif terkait hal ini. Perlu ada informasi yang bersifat objektif yang diberikan sehingga informasi yang diterima dapat berimbang bahkan dapat mencerahkan sehingga stigma negatif terhadap pelaku fraud/korupsi tidak dikaitkan dengan agama pelakunya terutama Islam, namun berpulang ke tabiat dari pelaku itu sendiri.

Penelitian terkait fraud dalam presfektif Islam masih sangat jarang diungkapnya secara utuh, banyak jurnal-jurnal baik innternasional maupun nasional yang mengungkapkan fraud dalam 
presfektif secara umum dan jikalau mengambil atau mengungkapkan fraud dari segi Islam hanya mengambil sebagian saja. Untuk itu perlu dilakukan kajian secara menyeluruh terkait fraud dalam perfektif Islam, dan jurnal ini mencoba untuk mengkaji hal tersebut.

\section{STUDI LITERATUR}

Agama Islam merupakan agama yang sempurna, sebagaimana ditegaskan dalam Surah AlMaidah'/5:3 sebagai berikut,

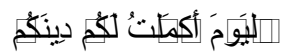 \\ "Pada hari ini telah Kusempurnakan untukmu agamamu"}

Ayat di atas, menegaskan bahwa umat Islam tidak boleh menambah atau mengurangi ajaran Islam karena telah sempurna (Jawas, 2007). Islam telah mengatur semua permasalahan umatnya. Dalam Islam ada 2 (dua) rujukan yang menjadi pedoman hidup umat Islam yaitu Al-Quran dan Hadist. Hal ini telah ditegaskan dalam Surah Al-Baqarah'/2:231 sebagai berikut,

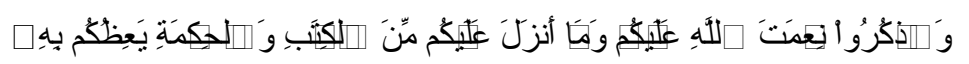

"Dan ingatlah ni'mat Allah padamu, dan apa yang telah diturunkan Allah kepadamu yaitu Al

Kitab dan Al Hikmah (As Sunnah). Allah memberi pengajaran kepadamu dengan apa yang diturunkan-Nya itu."

Selain ayat di atas, Allah Ta'ala juga mengabarkan hal serupa dalam Surah An-Nisa/4:113 sebagai berikut,

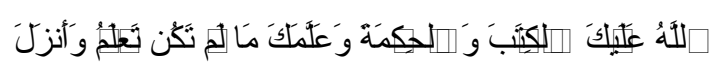

"Dan (juga karena) Allah telah menurunkan Kitab dan hikmah kepadamu, dan telah mengajarkan kepadamu apa yang belum kamu ketahui."

Kata Hikmah yang tercantum dalam ayat-ayat di atas maksudnya adalah Hadist atau Sunnah, Surah Al-Ahzab/33:34 menjelaskan hal tersebut sebagai berikut

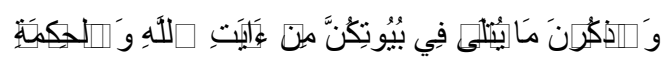

"Dan ingatlah apa yang dibacakan di rumahmu dari ayat-ayat Allah dan hikmah (sunnah nabimu)."

Yang dimaksud Hikmah pada ayat di atas adalah hadist atau sunnah (Al-Hilali, 2011). Dua rujukan tersebut menjadi pegangan umat Islam dalam menjalani aktifitas kesehariannya. Karena dalam keyakinan umat Islam, agama tidak bisa dipisahkan dalam kehidupan sehari-hari. Islam mengatur keseluruhan kehidupan melalui Al-Quran sebagaimana tercantum pada An-Nahl ayat 89;

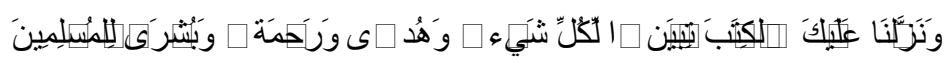

"Dan Kami turunkan kepadamu Al Kitab (Al-Qur'an) untuk menjelaskan segala sesuatu dan petunjuk serta rahmat dan kabar gembira bagi orang-orang yang berserah diri."

Dengan demikian Al-Quran merupakan petunjuk yang mengalahkan hasil cipta, pemikiran dan perundangan buatan manusia. (Musthafa, 2013). Islam mengatur hubungan antara manusia dengan Rabb-nya dan juga mengatur hubungan sesama mahluk. Dalam hal hubungan dengan manusia, Islam melarang perbuatan curang, hal ini ditegaskan dalam surah Al-Muthaffifin/83:1 sebagai berikut 


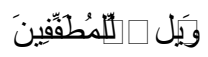

"Kecelakaan besarlah bagi orang-orang yang curang."

Ayat di atas, merupakan realita yang banyak dilakukan pedagang untuk mengambil untung yang besar dengan melakukan kecurangan dalam timbangan (Tuasikal, 2014). Dari penjelasan di atas, penulis merasa perlu untuk menggali terkait fraud atau kecurangan dalam perspektif Islam.

\section{Fraud dilihat dari prespektif umum}

Fraud dalam Kamus Besar Bahasa Indonesia (KBBI) dapat diartikan kecurangan, dimana kecurangan berasal dari kata curang yang dapat diartikan tidak jujur atau tidak lurus hati serta tidak adil, sedangkan mencurangi dapat diartikan berbuat curang terhadap seseorang atau menipu serta mengakali. Sedangkan kecurangan dapat diartikan perihal curang atau perbuatan yang curang atau ketidakjujuran serta keculasan. (KKBI, 2018).

Fraud is an act committed by individuals or groups which will harm people, organizations or companies by taking advantage of fabric for private and group benefits (Safuan, 2018).

Dapat dikatakan bahwa fraud adalah tindakan yang dikerjakan oleh individu ataupun kelompok yang berdampak merugikan antara lain orang, organisasi, atau perusahaan dengan modus mengambil keuntungan berupa materi untuk kepentingan pribadi dan kelompok.

Fraud can involve any criminality for gain that uses deception as its fundamental modus operandus (ACFE, 2004). Fraud bisa mencakup kejahatan apapun untuk keuntungan yang menggunakan penipuan sebagai modus operandus utamanya.

Fraud secara istilah dapat dikatakan sebagai bentuk kecurangan atau penipuan yang bertujuan memperoleh keuntungan secara material dan non material. (Yurmaini, 2017). Fraud merupakan tindakan berlawanan dengan kebenaran dan sengaja dilakukan demi mendapatkan sesuatu yang bukan merupakan hak oknum tersebut sehingga berakibat merugikan orang lain (Alfian, 2016).

\section{Jenis-jenis Fraud}

ACFE (the Association of Certified Fraud Examiners) menyatakan bahwa Fraud is split into 3 (three) typologies of action:

1. Asset Misappropriation includes the stealing or misappropriation of company's assets or property or other party. are often "this is often a sort of fraud that's most easily detected because it's tangible or the worth can be defined. (Defined value);

2. Fraudulent Statement include actions committed by a politician or executive of a corporation or agency to hide the financial conditions by doing financial engineering in financial statements to get benefit (window dressing);

3. Corruption. this is often the foremost difficult sort of fraud to detect because it involves cooperation with other parties like bribery and corruption, which is that the commonest fraud that happens in developing countries during which enforcement is weak and still lacks awareness of excellent governance in order that the factor of integrity remains questionable. this type of fraud usually can't be detected because the parties work together to require benefits (symbiosis mutualism). Conflict of interest, bribery, illegal gratuities, and economic extortion are included here. (Purnamasari \& Amaliah, 2015).

Dari pernyataan di atas, fraud atau kecurangan terbagi menjadi 3 bagian yaitu fraud terkait 1) Aset, 2) Laporan Keuangan, 3) Korupsi (Corruption). Hal tersebut dapat dijelaskan sebagai berikut fraud terkiat aset termasuk pencurian dan penyalahgunaan aset perusahaan, fraud jenis ini sangat mudah di deteksi dikarenakan aset tersebut jelas dan nilainya juga dapat diperkirakan. Sedangkan fraud terkait laporan keuangan adalah merekayasa laporan keuangan korporasi atau lembaga biasanya dilakukan karyawan atau eksekutif korporasi atau lembaga dengan tujuan mengelabui yang membacanya sehingga korporasi atau lembaga terlihat sehat dari segi keuangannya. Untuk korupsi, merupakan jenis penipuan yang sangat sulit untuk dideteksi karena melibatkan kerjasama antar pihak seperti suap dan korupsi, yang merupakan penipuan yang umum terjadi di negara berkembang di mana penegak hukum belum memiliki kekuatan dan belum sepenuhnya mempunyai 
kesadaran terkait tatakelola pemerintahan dengan baik sesuai yang diharapkan dimana aspek integritas terus dipertanyakan. Kecurangan semacam ini biasanya sulit dideteksi karena ada peran antar yang pihak bekerjasama untuk mengambil manfaat (simbiosis mutualisme). Konflik antar kepentingan, suap atau penyuapan, gratifikasi ilegal, dan pemerasan termasuk kedalam korupsi.

\section{Fraud dilihat dari prespektif Islam \\ Al-Qur'an menggambarkan tentang Fraud atau Kecurangan}

Fraud atau Kecurangan ditegaskan dalam Al-Quran dalam surat Al-Muthaffifin/83:1-3 Sebagai berikut;

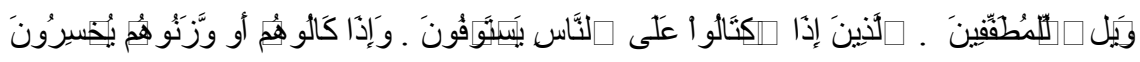

"Kecelakaan besarlah bagi orang-orang yang curang, (yaitu) orang-orang yang apabila menerima takaran dari orang lain mereka minta dipenuhi, dan apabila mereka menakar atau menimbang untuk orang lain, mereka mengurangi".

Ayat Qur'an di atas, ditafsirkan oleh hadist riwayat Nasa'i dan Ibnu Majah yaitu Ibnu Abbas menceritakan sesampainya Rasulullah di kota Madinah, masyarakat disana dikenal selalu melakukan kecurangan pada takaran. Sehingga Allah Ta'ala menurunkan firman-Nya: Kecelakaan besarlah bagi orang-orang yang curang. (Al-Muthaffifin/83:1) Setelah kejadian tersebut masyarakat disana telah berlaku baik dalam menggunakan takaran. (IbnuKatsir, 2013).

Selain itu, Al-Qur'an juga menganjurkan agar tidak berlaku curang. Salah satunya didalam surah Al-An'am/6:152 sebagai berikut

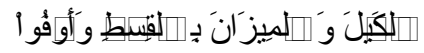

"Dan sempurnakanlah takaran dan timbangan dengan adil."

Dan juga didalam surah Ar Rahman/55:9 sebagai berikut

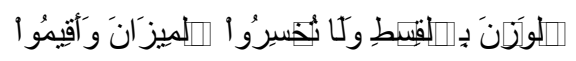

"Dan tegakkanlah timbangan itu dengan adil dan janganlah kamu mengurangi neraca itu."

Islam dengan tegas memerintahkan umatnya agar bermuamalah antar sesama manusia yaitu dengan keadilan dan keridhaan, salah satu bentuknya adalah dengan menyempurnakan timbangan dan takaran. (Minhal, 2013). Selain itu, dalam surah Al-Baqarah/2:188 sebagai berikut

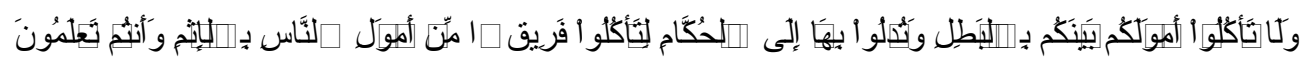

"Dan janganlah sebagian kalian memakan harta sebagian yang lain di antara kalian dengan jalan yang batil dan (janganlah) kalian membawa (urusan) harta itu kepada hakim, supaya kalian dapat memakan sebagian dari harta benda orang lain itu dengan (jalan berbuat) dosa, padahal kalian mengetahui."

Ibnu Abi Talhah telah meriwayatkan dari jalan Ibnu Abbas yang menjelaskan tentang ayat ini yaitu terkait seseorang pria yang mmpunyai hutang beruapa harta, sedangkan pemiutang (yang meminjamkan) tidak memegang bukti kuat. kemudian pria itu mengingkari hutangnya dan mengadukan hal ini kepada hakim, padahal dia mengetahui bahwa dia berhadapan dengan perkara yang benar, dan bahwa dirinya berada di pihak yang salah (berdosa) dan telah memakan harta haram. (IbnuKatsir, 2013).

Dalam ayat ini Allah Ta'ala secara tegas mengancam seseorang yang memakan atau mengambil harta orang lain (Naro, 2007). 


\section{Al-Hadist menggambarkan tentang Fraud atau Kecurangan}

Selain Al-Qur'an, beberapa hadist juga menggambarkan bagaimana fraud atau kecurangan, seperti dalam hadist riwayat Muslim sebagai berikut

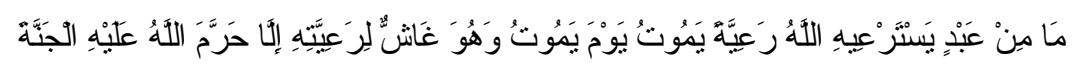

"Rasulullah shallallahu 'alaihi wa sallam bersabda: Barangsiapa diberi beban oleh Allah untuk memimpin rakyatnya lalu mati dalam keadaan menipu rakyat, niscaya Allah mengharamkan Surga atasnya."

Dalam hadist ini Rasulullah Shalallahu 'Alaihi Wassalam menerangkan dan mengancam pemimpin yang berbuat curang atau menipu rakyatnya/bawahan yang dipimpinnya. Hal ini menegaskan bahwa pemimpin harus memiliki komitmen tidak akan melakukan kecurangan atau berbuat curang, jika pemimpin tersebut melakukannya maka jelas ancamannya adalah neraka. (Gunarsa, 2014). Fraud atau kecurangan juga digambarkan dalam hadist riwayat Muslim sebagai berikut

$$
\text { وَمَنْ غَشَنَّنَا فَلْنَس مِنَّا }
$$

"Dan barangsiapa menipu kami, maka dia bukan golongan kami"

Fraud atau kecurangan juga dijelaskan dalam hadist Sunan Abu Daud sebagai berikut;

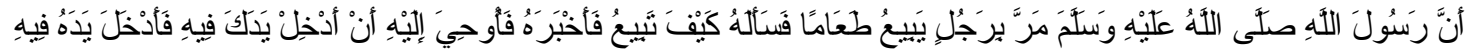

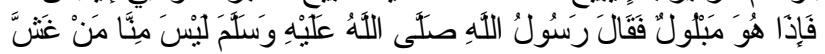

"Rasulullah shallallahu 'alaihi wa sallam melewati seorang laki-laki yang menjual makanan, kemudian beliau bertanya kepadanya: "Bagaimana engkau berjualan?" Kemudian orang tersebut memberitahukan kepada beliau bagaimana ia berjualan. Kemudian Rasulullah shallallahu 'alaihi wa sallam diberi wahyu: "Masukkan tanganmu ke dalam makanan tersebut!" Kemudian beliau memasukkan tangannya ke dalamnya, dan ternyata makanan tersebut basah. Lalu Rasulullah shallallahu 'alaihi wa sallam bersabda: "Bukan dari golongan kami orang yang menipu."

Hadist di atas menceritakan bahwa ketika Nabi shallallahu 'alaihi wa sallam berangkat bersama rombongan para sahabat ke pasar untuk melakukan pengecekan barang-barang dagangan. Saat beliau melewati gundukan makanan, beliau kemudian memasukkan tangannya dan mendapati bagian dalam gundukan tersebut basah. Dalam Islam, hal ini masuk ke dalam kategori curang. (Gunarsa, 2014). Selain itu, Islam juga melarang umatnya untuk berbuat kecurangan yaitu dengan menerima suap atau memberi suap (Badri, 2017), seperti yang termaktub dalam Hadist Ibnu Majah sebagai berikut

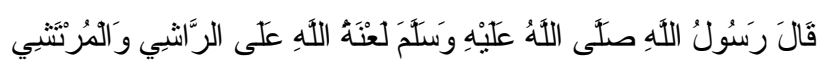

"Rasulullah shallallahu 'alaihi wa sallam bersabda: "Allah melaknat penyuap dan penerima suap."

Hadist yang semakna diriwayatkan oleh Ahmad, sebagai berikut;

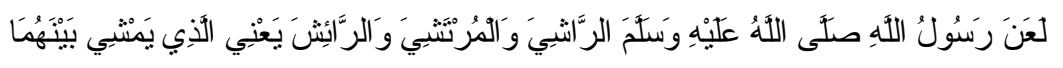

"Rasulullah shallallahu 'alaihi wa sallam melaknat orang yang menyuap, yang disuap dan perantaranya". 
Hadist di atas, menjelaskan larangan terkait suap-menyuap karena ini merupakan bagian fraud atau kecurangan. (al-Atsari, 2018). Hadist lain terkait kecurangan atau fraud seperti yang diriwayatkan oleh Muslim sebagai berikut,

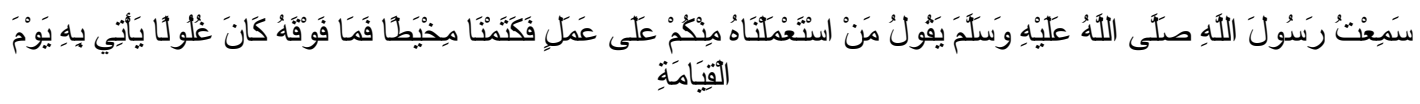

"Rasulullah shallallahu 'alaihi wa sallam bersabda: "Barangsiapa dari kalian yang aku angkat atas suatu amal, kemudian dia menyembunyikan dari kami (meskipun) sebuah jarum, atau sesuatu yang lebih kecil daripada itu, maka hal itu termasuk ghulul (pencurian) yang pada hari kiamat akan ia bawa."

Hadist di atas, merupakan peringatan bagi orang yang diberikan amanah kemudian mengambil yang bukan menjadi haknya dapat dikatakan korupsi atau mencuri (Syarifuddin, 2010).

\section{METODE}

Dalam penelitian ini, metode yang digunakan adalah metode kulitatif dengan pendekatan studi literatur dimana peneliti mencari literatur terkait fraud/kecurangan baik dari Al-Qur'an, Hadist serta perkataan para ulama-ulama Islam melalui referensi buku dan jurnal, serta mencari literatur terkait fraud/kecurangan yang bersifat umum melalui jurnal-jurnal penelitian baik jurnal internasional maupun nasional. Kemudian melakukan pembahasan serta memberikan kesimpulan terhadap permasalahan yang sedang diteliti. Studi Literatur atau literature review merupakan pendekatan dengan cara dikumpulkan dengan tujuan untuk diambil intisari dari penelitian sebelumnya dan diambil analisanya untuk memberikan beberapa gambaran ataupun kesimpulan dari para ahli yang tercantum dalam teks. (Snyder, 2019).

Startegi dalam pencarian literatur yaitu dengan mengoptimalkan google search engine dengan kata kunci fraud atau kecurangan dalam kacamata Islam. Literatur yang digunakan dalam penelitian ini yaitu rentan waktu 2010 sampai dengan 2020. Dengan kriteria jurnal internasional maupun jurnal nasional baik yang bereputasi maupun yang tidak atau baik yang berakreditasi ataupun tidak berakreditasi, jurnal dalam bahasa Indonesia ataupun bahasa asing khususnya bahasa Inggris.

Untuk memperjelas hasil dari studi literatur ini, maka abstrak dan full-text dari jurnal yang dijadikan bahan penelitan dibaca dan dicermati dengan seksama. Kemudian dianalisis dan dilakukan pembahasan serta diberikan kesimpulan.

\section{HASIL}

Dalam penelitian kali ini dilakukan batasan studi agar hasil dari penelitian ini dapat bermanfaat dan tidak keluar dari permasalahan yang sedang diteliti. Adapun yang menjadi batasan studi akan dibahas dalam penelitian kali ini fraud yang dikenal dalam Islam. Hasil dari penilitian ini dapat dikemukakan bahwa fraud/kecurangan telah dikenal dalam dunia Islam, praktek dan istilah terkait fraud/kecurangan antara lain; a) Tadlis/Taghrir; b) Tadlis/Taghrir; c) Gharar; d) Khiyanah/ Ghulul; e) Risywah; dan f) Ihtikar.

\section{PEMBAHASAN}

Praktek dan istilah terkait fraud dalam Islam adalah sebagai berikut, "The theory of fraud in Islam has been assigned with many various terminologies. the main common ones include taghrir, tadlis, ghabn, ghubn, ghushsh and gharar, while the fewer common include khallab, khiyanah, ihtiyal, tahayul, tadlil, iham, nasb and khadi'a, which all vary in connotation from fraud, scam, cheating, laceration, misrepresentation, duplicitous to imbalance." (Jabbar, 2012) konsep penipuan dalam Islam ditetapkan dengan banyak terminologi yang berbeda. Yang paling umum termasuk taghrir, tadlis, ghabn, ghubn, ghushsh dan gharar, sementara yang kurang umum termasuk khallab, khiyanah, ihtiyal, tahayul, tadlil, iham, nasb dan khadi'a, semua itu merupakan variasi dari penipuan, tipuan, penipuan, lesi, salah tafsir, penipuan ketidakseimbangan.

Selain jurnal di atas, istilah fraud atau kecurangan dapat dilihat dalam jurnal berikut, "In Islamic allowed manuscripts fraud (tadlis or khilaba), laceration or misrepresentation (ghabn), gross 
misrepresentation (ghabn fahish), trickery (ghushsh), imbalance (gharar), and deception (taghrir) are used interchangeably on mean fraud. Likewise there are few texts that also question fraud but less regularly used like khallab, khiyanah, ihtiyal, tahayul, tadlil, iham, nasb, and khadi'a which all vary in connotation from fraud, trickery, deception, lesion, misrepresentation, swindling to imbalance" (Ibrahim, Man, \& Noor, 2013). Pernyataan di atas menjelaskan bahwa kecurangan atara lain (tadlis atau khilaba), keliru (ghabn), ghabn fahish, tipuan (ghushsh), tidak seimbang (gharar), dan trik (taghrir) yang dipakai dengan cara diganti dengan tujuan untuk melakukan fraud. Selain daripada itu, terdapat beberapa kata merujuk kepada istilah fraud namiun masib belum umum digunakan antara lain khallab, khiyanah, ihtiyal, tahayul, tadlil, iham, nasb, dan khadi'a, semua itu yang merupakan variasi dari makna dari penipuan, tipu, curang, lesi, keliru, manipulasi neraca keuangan.

\section{Tadlis/Taghrir}

Tadlis//Taghrir atau penipuan. Tadlis/Taghrir merupakan istilah bahasa (Arab) merupakan mashdar kata dallasa-yudallisu-tadliisan mknanya belum jelas sesuatunya, menutupi, dan penipuan. Tadlis/Taghrir maknanya bukan menjual barang yang memiliki kerusakan, tapi menyimpan informasi kerusakan barang dan informasi ini merugikan pembeli atau pelanggan sehingga informasi yang dimiliki oleh pihak yang sedang melaukan transaksi tidak simetris (asymmetric information). Maka jelas tadlis bukan merupakan asymmetric information, namun tindakan salah satu pihak menyembunyikan informasi ketika melakukan transaksi dan menjadi penyebab keadaan asymmetric information. (Fauzi, 2017). Tadlis merupakan upaya pihak tertentu menyembunyikan informasi ketika bertransaksi sehingga merugikan pihak tertentu. (Taufiq, 2016).

Tadlis/Taghrir dalam transaksi dapat dikaitkan kedalam 4 hal yaitu kualitas, kuantitas, harga serta waktu penyerahannya. (Fatimah, 2016). Tadlis/Taghrir tidak hanya pada pedagang namun juga pada pembeli seperti menggunakan alat pembayaran yang tidak sah. (Madjid, 2018).

Taghrir secara terminologi menurut Rahman seperti yang dikutip oleh Syamsul Hilal dalam jurnalnya yaitu tindakan secara serampangan namun minim pengetahuan atau orang yang mengambil risiko dari perilakunya tanpa memperdulikan risiko yang akan dihadapi. Tadlis/Taghrir disebabkan terdapat informasi yang tidak lengkap yang dialami oleh keduabelah pihak baik penjual dan maupun pembeli (Hilal, 2014).

Dari beberapa pengertian terkait Tadlis/Taghrir di atas, dapat diambil kesimpulan bahwa Tadlis/Taghrir adalah adalah suatu tindakan yang menyembunyikan cacat atau kelemahan pada suatu barang dalam suatu transaksi yang dapat merugikan pihak tertentu dalam transaksi jual beli.

\section{Ghabn}

Ghabn yaitu penjual memberikan tawaran kepada pembeli dengan harga diatas rata-rata harga pasar (market price) tanpa di sadari atau diketahui oleh pihak pembeli. Ghabn di bagi menjadi 2 yaitu ; Ghabn Fahish (Excessive) dan Ghabn Qalil (Negligible) (Ichsan, 2015). Ghabn terjadi karena ketidaktahuan konsumen atas harga barang dan dimanfaatkan oleh penjual untuk meraih untung besar. Biasanya terkait penetapan harga di atas kewajaran dan di atas harga pasar. (Syukur \& Syahbudin, 2017).

Ghabn secara bahasa yaitu pengurangan. Mengambil istilah dari ilmu fiqih, artinya tidak terjadi keseimbangan antara obyek akad (barang) dan harganya, seperti lebih tinggi atau lebih rendah dari harga sesungguhnya. (Alia, 2015). Dapat diambil kesimpulan bahwa Ghabn menjual barang dengan harga di atas pasar dengan memanfaatkan ketidaktahuan konsumen terhadap harga barang tersebut.

\section{Gharar}

Gharar menurut Warde seperti yang dikutip oleh Santosa dan Muttaqin dalam jurnalnya menyatakan bahwa gharar mengacu pada transaksi yang tidak jelas, yaitu transaksi yang dikondisikan pada keadaan dan kondisi yang tidak pasti. (Santosa \& Muttaqin, 2015). Gharar diartikan seluruh bentuk transaksi yang mengandung unsur ketidakjelasan, ketidakpastian dan pertaruhan atau perjudian sehingga tidak ada kepastian dalam transaksi tersebut. (Hosen, 2009).

Gharar adalah seluruh akad yang terkandung didalamnya ketidakjelasan atau keraguan tentang 
ada tidaknya komoditi yang menjadi objek akad, ketidakjelasan akibat, dan adanya bahaya yang mengancam antara untung dan rugi; pertaruhan, atau perjudian dan transaksi. (Najamuddin, 2014).

Gharar dapat diartikan dengan risiko, penanggungan, mengelabui atau memperdaya, tidak mengerti dan mencakup semua kasus penipuan serta semisalnya demi menggapai sasaran yaitu memperoleh suatu persoalan atau kekayaan dengan perbuatan tidak dibenarkan dan tidak semestinya. (Awang, 2012). Dari penjelasan di atas, dapat disimpulkan bahwa Gharar adalah bentuk transaksi yang belum jelas dan mengandung unsur pertaruhan atau perjudian yang dapat menimbulkan kerugian.

\section{Khiyanah/ Ghulul}

Khiyanah secara etimologis menurut Dahlan seperti yang dikutip oleh Fazzan dalam jurnalnya memiliki arti transformasi seseorang menjadi curang (syar). Merujuk al-Raghib al-Isfahani, "khiyanah" merupakan perbuatan ingkar janji atau amanah yang telah diberikan kepadanya.

Ungkapan "khiyanah" diperuntukan untuk orang yang melanggar atau mengambil hak pihak lain, dengan modus pembekuan dengan sepihak perjanjian yang sudah disepakati, terkhusus dalam perkara muamalah (Fazzan, 2015).

"Khiyanah" juga di artikan ghulul (korupsi), secara umum digunakan untuk setiap pengambilan harta oleh seseorang secara khianat, atau tidak dibenarkan dalam tugas yang diamanahkan kepadanya (tanpa seizin pemimpinnya atau orang yang menugaskannya). (Syarifuddin, 2010). Korupsi merupakan kejahatan yang dapat dikategorikan ke dalam khiyanah, karena pelaku korupsi tersebut telah menyelewengkan kepercayaan yang diamanahkan. (Syamsuri, 2011).

Ghulul juga diartikan sebagai penyalahgunaan jabatan yang diamanahkan kepadanya. (Sumarwoto, 2014). Dari keterangan di atas, dapat disimpulkan bahwa khiyanah/ghulul adalah pengkhianatan terhadap amanah yang diberikan dengan menyalahgunakan untuk mendapatkan keuntungan demi kepentingan pribadi.

\section{Risywah}

Secara terminologi, Risywah (Suap) merupakan suatu penyerahan baik berwujud harta ataupun barang yang lain yang diberikan kepada pejabat atau yang memegang kebijakan/kekuasaan demi menghalalkan (atau melancarkan) yang buruk dan mengharamkan yang baik atau memperoleh keuntungan dari cara yang tidak bertentangan dengan hukum (Haryono, 2016).

"Risywah" atau suap dapat membuat diam seseorang dari hal yang dibenarkan. Namun merujuk terminologi fiqh, suap merupakan segala hal yang dikirimkan oleh seseorang yang ditujukan kepada hakim atau selain hakim supaya hakim atau selain hakim yang memiliki wewenang untuk memutuskan suatu persoalan bagi (kepentingan)nya atau agar hakim atau selain hakim tersebut untuk mlaksanakan keinginannya. (Sumarwoto, 2014). Risywah (Suap) atau uang komisi termasuk bagian dari bentuk korupsi investif (investive corruption). (Darlis, 2017).

Dapat disimpulkan, Risywah atau suap adalah segala sesuatu yang diberikan kepada pejabat atau yang memiliki kekuasaan baik harta atau benda dengan tujuan mengikuti kemauan yang memberikan suap tersebut.

\section{Ihtikar}

Ihtikar (Menimbun) adalah mengumpulkan makanan dan barang yang dapat dikonsumsi kemudian ditahan untuk menunggu waktu naiknya harga (Muslim, 2010).

"Ihtikar" tidak dihalalkan dalam ajaran Islam karena merupakan tindakan yang dapat mendatangkan kerugian bagi masyarakat, adalah dengan cara melakukan penimbunan dan menahan benda/sesuatu agar tidak ada dipasaran (langka), ketika benda/sesuatu tersebut menjadi sulit ditemukan, kemudian pemilik benda/sesuatu tersebut menjajakan menggunakan harga diluar harga normal alias dengan harga tinggi. Walhasil, laba yang didapat pemilik barang/sesuatu dapat berlipat ganda. Dari sini maka jelaslah bahwa perbuatan demikian kurang menguntungkan pelanggan. (Masruroh, 2015).

\section{KESIMPULAN}

Berdasarkan pembahasan di atas, maka dapat diketahui bahwa Islam sangat memperhatikan 
bagaimana hubungan antar individu melalui aturan yang telah berlaku di dalam Al-Qur'an dan AlHadist. Islam juga sangat melarang umatnya untuk berbuat kecurangan (fraud) dalam kehidupan keseharian yang jika hal tersebut dilakukan maka akan terjadi kerusakan dalam tatanan hidup bermasyarakat, dan jika tetap melakukan hal tersebut (fraud) maka akan ada ancaman dan hukuman yang akan diterima individu yang melakukannya. Dalam jurnal ini, terdapat informasi terkait fraud dari sisi pandangan Islam, namun masih banyak lagi informasi terkait fraud yang belum terungkap dalam jurnal ini. Semoga penelitian ini dapat dilanjutkan dengan mengungkapkan fraud dalam pandangan Islam lebih dalam dan luas lagi sehingga dapat bermanfaat bagi masyarakat.

\section{REFERENSI}

ACFE. (2004). Fraud. Retrieved from ACFE (Association of Certified Fraud Examiners): http://www.acfe.com/fraud-101.aspx, Nov 20, 2020.

al-Atsari, A. I. (2018). Suap, Mengundang Laknat. Retrieved from Al-Manhaj: https://almanhaj.or.id/7004-suap-mengundang-laknat.html, Nov 15, 2021.

Alfian, N. (2016). Nilai-Nilai Islam Dalam Upaya Pencegahan Fraud. AKTIVA Jurnal Akuntansi dan Investasi, Vol. 1. No. 2, 205-218. doi:10.35835/aktiva.v1i2.143

Al-Hilali, S. I. (2011). Sunnah, Antara Musuh Dan Pembelanya. Retrieved from Al-Manhaj: https://almanhaj.or.id/3024-sunnah-antara-musuh-dan-pembelanya.html. Oct 10, 2020.

Alia, C. L. (2015). Akad Yang Cacat Dalam Hukum Perjanjian Islam. Premise Law Journal, 1-17.

Alquran. (2018). Quran Online Terjemahan Perkata, Tajwid, Latin dan Asbabun Nuzul. AlquranIndonesia.com.

Awang, A. H. (2012). Gharar Dalam Perspektif Fiqh Al-Hadith Analisis Terhadap 'Illah Dan Prinsip. H A D I S Jurnal Ilmiah Berimpak, 63-93.

Badri, M. A. (2017). Hadiah, Gratifikasi dan Suap. Retrieved from Komunitas Pengusaha Muslim Indonesia: https://pengusahamuslim.com/6003-hadiah-gratifikasi-dan-suap.html. Nov 10, 2020.

Darlis. (2017). Inspirasi Al-Quran Dalam Pemberantasan Korupsi. Rausyan Fikr, Vol. 13, No.1, 49-72. doi:10.24239/rsy.v13i1.90

Fatimah, S. (2016). Analisis Praktek Tadlis Pada Masyarakat Kota Makassar (Studi Lapangan Pedagang Buahan-Buahan Di Kota Makassar). Jurnal Ilmiah BONGAYA (Manajemen \& Akuntansi), 218-235.

Fauzi, A. S. (2017). Transaksi Jual-Beli Terlarang: Ghisy atau Tadlis Kualitas (Penipuan atau Kecurangan). Mizan: Journal of Islamic Law, Vol. 1 No. 2, 41-54. doi: $10.32507 /$ mizan.v1i2.9

Fazzan. (2015). Korupsi Di Indonesia Dalam Perspektif Hukum Pidana Islam. Jurnal Ilmiah ISLAM FUTURA, Vol. 14. No. 2, 146-165. doi:10.22373/jiif.v14i2.327

Gunarsa, A. K. (2014). Perbuatan Curang, Faktor dan Dampaknya. Retrieved from Muslim.or.id: https://muslim.or.id/22590-perbuatan-curang-faktor-dan-dampaknya.html, Nov 10, 2020.

HaditsSoft. (2018). 14 Buku Hadits. HaditsSoft. Retrieved from http://haditssoft.netne.net/, Oct 10, 2020

Haryono. (2016). Risywah (Suap-Menyuap) Dan Perbedaannya Dengan Hadiah Dalam Pandangan Hukum Islam (Kajian Tematik Ayat dan Hadis Tentang Risywah). Al-Mashlahah, Jurnal Hukum Dan Pranata Sosial Islam, Vol. 4. No. 07, 429-450. doi:10.30868/am.v4i07.155

Hilal, S. (2014). Konsep Harga Dalam Ekonomi Islam (Telah Pemikiran Ibn Taimiyah). ASAS, Vol. 6. No. 2, 16-28. doi:10.24042/asas.v6i2.1718

Hosen, N. (2009). Analisis Bentuk Gharar Dalam Transaksi Ekonomi. Al-Iqtishad, Vol. I, No. 1, 53-64. doi:10.15408/aiq.v1i1.2453

IbnuKatsir. (2013). Tafsir Ibnu Katsir. kampungsunnah.com.

Ibrahim, S. S., Man, N. C., \& Noor, A. H. (2013). Fraud: An Islamic Perspective. The 5th International Conference on Financial Criminology (ICFC), (pp. 446-457).

Ichsan, N. (2015). Kerja, Bisnis Dan Sukses Menurut Islam. The Journal of Tauhidinomics, Vol. 1 No. 2 , 167-182. doi:10.15408/thd.v1i2.8434 
Jabbar, S. F. (2012). Insider Dealing: Fraud In Islam? . Journal of Financial Crime , Vol. 19(Iss: 2), pp. 140 - 148. doi: 10.1108/13590791211220412

Jawas, Y. A. (2007). Islam Adalah Agama Yang Sempurna. Retrieved from Al-Manhaj: https://almanhaj.or.id/2043-islam-adalah-agama-yang-sempurna.html, Nov 13, 2020.

KKBI. (2018). Kecurangan. Retrieved from KKBI (Kamus Besar Bahasa Indonesia): https://kbbi.web.id/curang, Oct 10, 2020.

Madjid, S. S. (2018). Prinsip-Prinsip (Asas-Asas) Muamalah. J-HES Jurnal Hukum Ekonomi Syariah, Vol. 2, No. 1, 14-28. doi:10.26618/j-hes.v2i1.1353

Masruroh, N. (2015). Larangan Ihtikar di Indonesia (Kajian Tentang Efektifitas UU Anti Monopoli di Indonesia). Interest, Vol.13, No. 1, 81-98.

Minhal, A. (2013). Curang Dalam Timbangan Dan Takaran, Mengundang Kerusakan Di Dunia Dan Celaka di Akherat. Retrieved from Al-Manhaj: https://almanhaj.or.id/3654-curangdalam-timbangan-dan-takaran-mengundang-kerusakan-di-dunia-dan-celaka-diakherat.html, Nov 19, 2020.

Muslim, M. B. (2010). Ihtikar Dan Dampaknya Terhadap Dunia Ekonomi. Jurnal Studi Al-Qur'an: Membangun Tradisi Berfikir Qur'ani, Vol. 6. No. 1, 1-14.

Musthafa, A. (2013). Petunjuk Terbaik Hanya Ada Di Al-Qur'an. Retrieved from Al-Manhaj: https://almanhaj.or.id/3492-petunjuk-terbaik-hanya-ada-di-al-quran.html, Oct 12, 2020.

Najamuddin. (2014). Transaksi Gharar dalam Muamalat Kontemporer. Jurnal Syariah, Vol. 2, No. 1. doi:10.32520/.v2i1.20

Naro, A. H. (2007). Hukum Seputar Suap Dan Hadiah. Retrieved from Al-Manhaj: https://almanhaj.or.id/2283-hukum-seputar-suap-dan-hadiah.html, Oct 20. 2020

Purnamasari, P., \& Amaliah, I. (2015). Fraud Prevention: Relevance To Religiosity And Spirituality In The Workplace. Procedia - Social and Behavioral Sciences, 827 - 835. doi: 10.1016/j.sbspro.2015.11.109

Safuan. (2018). Fraud and Anti Fraud in Port Sector. Asia Pasific Fraud Journal., Vol. 3, 145-152. doi:10.21532/apfjournal.v3i1.69

Safuan, S., \& Budiandru, B. (2019). Modus Kecurangan \& Program Anti Kecurangan di Pelabuhan (Studi Kasus Pelabuhan di Jakarta). Owner : Riset Dan Jurnal Akuntansi, 3(2), 54-65. doi:10.33395/owner.v3i2.131

Santosa, P. B., \& Muttaqin, A. A. (2015). Larangan Jual Beli Gharar: Tela'ah Terhadap Hadis Dari Musnad Ahmad Bin Hanbal. EQUILIBRIUM, Jurnal Ekonomi Syariah, Vol. 3. No. 1, 157173. doi:10.21043/equilibrium.v3i1.1277

Snyder, H. 2019. 'Literature review as a research methodology: An overview and guidelines'. Journal of Business Research, 104, pp. 333-339, https://doi.org/10.1016/j.jbusres.2019.07.039.

Sumarwoto. (2014). Tinjauan Hukum Islam Terhadap Tindak Pidana Korupsi. RECHSTAAT Ilmu Hukum Fakultas Hukum UNSA, Vol. 8, no. 1, 1-12.

Syamsuri. (2011). Menggagas Fikih Anti Korupsi. al-Daulah, Jurnal Hukum Dan Perundangan Islam, 181-206. doi:10.15642/ad.2011.1.2.181-206

Syarifuddin, A. H. (2010). Mewaspadai Bahaya Korupsi. Retrieved from Al-Manhaj: https://almanhaj.or.id/2673-mewaspadai-bahaya-korupsi.html , Sept 05, 2020.

Syukur, P. A., \& Syahbudin, F. (2017). Konsep Marketing Mix Syariah. Jurnal Ekonomi dan Perbankan Syariah, Vol. 5. No.1, 71-94. doi:10.46899/jeps.v5i1.167

Taufiq. (2016). Tadlis Merusak Prinsip 'Antaradhin Dalam Transaksi. JURIS (Jurnal Ilmiah Syariah) Vol. 15, No. 1, 1-10. doi:10.31958/juris.v15i1.483

Tuasikal, M. A. (2014). Pedagang yang Bermain Curang dalam Timbangan. Retrieved from Rumaysho: $\quad$ https://rumaysho.com/8576-pedagang-yang-bermain-curang-dalamtimbangan.html, Oct 10, 2020.

Tranparency International. Corruption Perceptions Index. Retrieved from transparency.org: https://www.transparency.org/en/cpi/2020/index/nzl\#, Feb 03, 2021.

Yurmaini. (2017). Kecurangan Akuntansi (Fraud Accounting) Dalam Perspektif Islam. Jurnal Akuntansi dan Bisnis, Vol. 3 No. 1, 93-104. doi:10.31289/jab.v3i1.428 